\title{
COMENTÁRIO
}

\section{ANENCEFALIA: INTERRUPÇÃo DA GRAVIDEZ É UMA Liberdade de Escolha da Mulher? ${ }^{(*)}$}

\author{
ANENCEPHALY: IS THE INTERRUPTION OF \\ PREGNANCY A FREEDOM CHOICE OF WOMEN?
}

\author{
José Manoel de Souza Marques ${ }^{(* *)}$
}

\section{INTRODUÇÃO}

Trata-se de um estudo qualitativo para análise do tema sob a luz dos direitos constitucionais, como o direito à saúde e a liberdade de escolha da mulher, visando à construção de um conceito médico-jurídico para o caso e auxiliando, assim, os atores envolvidos nesse dilema em suas tomadas de decisão.

Para alcançar tais pretensões, foram realizadas pesquisas bibliográfica, documental e jurisprudencial, destacando-se a medida cautelar em arguição de descumprimento de preceito fundamental n. 54-8 DF (ADPF n. 54-8 DF), cujo relator é o ministro Marco Aurélio de Mello.

As publicações foram analisadas e delas foram extraídas as informações importantes para este estudo.

(*) Monografia apresentada no Curso de Especialização em Direito Sanitário, da Fundação Oswaldo Cruz - Brasília.

$\left.{ }^{(* *}\right)$ Médico do Ministério da Saúde e da Secretaria de Estado de Saúde Pública do Pará, especialista em Saúde Pública, Medicina do Trabalho e Direito Sanitário. E-mail: <josemanoelmarques@ig.com.br>. Recebido em 25.06.08. Revisado em 31.10.08. Aprovado em 15.01.09. 


\section{DO DIREITO CONSTITUCIONAL}

A Constituição Federal de 1988 define no art. 1º, inc. III a dignidade da pessoa humana como um valor fundamental para a construção do Estado Democrático de Direito no país, assegura a participação popular e trata a educação e a saúde como dever do Estado e direito de todos. Prevendo também que os direitos sociais devam ser efetivados, não se constituindo em finalidade, mas rotina da prática dos direitos sociais.

O Brasil é um Estado Democrático de Direito, pois tem a priori o Poder Constituinte, no exercício legal e legítimo, a fim de que os cidadãos ativos estabeleçam o bem comum de acordo com os preceitos da igualdade social, da soberania do povo e da integralidade do conjunto orgânico dos direitos humanos. ${ }^{(1)}$

A Constituição estabelece como direito fundamental a liberdade de religião (inc. VI, VII e VII do art. 5ํ) e, dessa maneira, o Estado brasileiro definiu-se como um Estado laico, que pode arbitrar de modo imparcial, e na forma da lei, nos conflitos entre grupos religiosos, não tomando partido por uma ou outra religião. Logo, a ordem jurídica em um Estado Democrático de Direito não pode se converter na voz exclusiva de uma única religião. A interpretação constitucional deve primar pelo respeito a princípios e racionalidade constitucionais, conferindo força normativa à Constituição. ${ }^{(2)}$

Da globalização e dos avanços tecnológicos, surgem consequências econômicas, políticas e sociais que requerem uma nova conduta ética que reconheça o "dever de cuidar", dentro e além das fronteiras, e uma nova negociação entre os indivíduos. Dessa forma, o maior desafio contemporâneo é a construção de uma ordem social justa, à luz do conhecimento obtido da evolução tecnológica, talvez, e não só por isso, é possível pensar e falar em um novo cenário. ${ }^{(3)}$

O "dever de cuidar", neste caso, nada mais é que cumprir os preceitos constitucionais referenciados no art. 23, inc. II, que estabelece a competência comum dos três níveis de governo de cuidar da saúde.

A Lei Orgânica da Saúde (Lei n. 8.080/90) no enunciado de seus arts. $2^{\circ}$ e $3^{\circ}$, diz que o Estado deve garantir o direito à saúde referindo-se às causas determinantes e condicionantes da saúde. Em consequência, o Estado pode intervir em fontes causadoras de doenças que interferem na saúde do indivíduo e da coletividade. Deve ser garantido a todos, pelo Estado, o cuidado de sua "doença", sendo que o direito à saúde começa, entre outros, pelo direito de não ficar doente mediante à adoção de medidas que reduzam o agravo à saúde.

(1) SILVA, J. A. Curso de direito constitucional positivo. 22. ed. São Paulo: Malheiros Ed., 2003.

(2) DINIZ, D.; DIAULAS, C. R. Aborto por anormalia fetal. Brasília: Letras Livres, 2004.

(3) SEBASTIANI, M. Analisis ético bajo el concepto del feto como paciente en los casos de anencefalia. Lexis NexisJurisprudência Argentina, Buenos Aires, n. 4, jul. 2003. 
Nesse sentido, as ações de saúde vão na direção do controle do risco sanitário - probabilidade de ocorrência de danos à saúde individual ou coletiva, podendo esse dano ser a própria doença ou um outro evento que leve à doença (vulnerabilidade).

\section{DO DIREITO À VIDA}

A palavra vida é conceituada em nossos dicionários, entre outras acepções como o período entre o nascimento e a morte.

O Pacto Internacional sobre Direitos Civis e Políticos reza que "O direito à vida é inerente à pessoa humana. Este direito deverá ser protegido pela lei, ninguém poderá ser arbitrariamente privado de sua vida" (Parte III, art. 6).

O Art. 5º, caput da Constituição, garante, entre outros a inviolabilidade do direito à vida. Nesse sentido, Miranda ${ }^{(4)}$ assegura que "o direito à vida é inato; quem nasce com vida, tem direito a ela". O direito à vida, pois, já que é inerente à pessoa humana, surge com o nascimento e finda com a morte. Correndo o risco da redundância, é de se concluir que só tem direito à vida a pessoa humana que já nasceu e que, portanto, já vive.

Assim, não há que se falar em direto à vida do nascituro, posto que ainda não se trata de pessoa humana, não ocorreu o fato que fará surgir seu direito à vida, ou seja: o nascimento. O Estado, entretanto, tem interesse que o feto nasça, realizando seu potencial e passando a ser titular do direito à vida e da dignidade da pessoa humana.

Ainda sobre o tema, convém destacar que: "o feto e o cadáver não possuem dignidade da pessoa humana (já que pessoas humanas não são), entretanto, possuem uma dignidade relativa. $O$ feto pelo que ele pode vir a ser e o cadáver pelo que foi”. (5)

Deve-se existir a proteção do nascimento de um feto portador de deficiência, mesmo que venha a ser uma pessoa que possa ter alguma limitação, o problema, aqui, refere-se às anomalias incompatíveis com a vida, onde não haverá sobrevivência do feto.

O aborto seletivo ocorre no caso de uma má formação fetal, o que faz com que a gestante ou o casal deseje interromper a gestação. Há uma seleção, como na eugenia, com a diferença de que o procedimento é realizado com o consentimento da gestante e por incompatibilidade com a vida extra-

(4) MIRANDA, P. Tratado de direito privado: parte especial. 3. ed. Rio de Janeiro: Editor Borsoi, 1971. t. 7.

(5) PONTES, M. S. A anencefalia e o crime de aborto: atipicidade por ausência de lesividade. Disponível em: <http://jus2.uol.com.br/Doutrina/texto.asp?id=7538>. Acesso em: 24 nov. 2006. 
-uterina do feto. Assim, o aborto seletivo trata de forma diferente os casos em que o feto vai se tornar uma criança portadora de deficiência dos casos nos quais o feto não possui qualquer viabilidade para vida extra-uterina.

\section{BIOÉTICA E BIODIREITO}

A bioética, literalmente a ética da vida, tem como objeto garantir que sejam efetuadas, dentro de padrões éticos e de respeito à dignidade humana, todas as intervenções médicas. Nas situações emergentes, há conflitos originados pela contradição verificada entre o progresso biomédico e os limites da cidadania e dos direitos humanos, como fecundação assistida, doação e transplante de órgãos e tecidos, clonagem e engenharia genética. A tarefa da bioética é harmonizar o uso das ciências biomédicas e suas tecnologias com os direitos humanos, até que, com o ordenamento jurídico dessas situações, surge o biodireito. ${ }^{(6)}$

O biodireito salienta que a verdade científica não poderá sobrepor-se à ética e ao direito, assim como o progresso científico não poderá ocultar crimes contra a dignidade humana sem limites jurídicos e traçar os destinos da humanidade. Isto requer a elaboração de normas que tragam respostas e criem condições satisfatórias, atendendo às novas necessidades ora surgidas e defendendo a pessoa humana da terrível ameaça de passar a ser coisa ${ }^{(7)}$. A bioética e o biodireito estabelecem um vínculo com a justiça, para qual a vida humana não pode ser uma questão de mera sobrevivência física, mas sim, de "vida com dignidade".

Com os avanços científicos e ponderações ético-jurídicas, o diagnóstico pré-natal de anomalias fetais teve um grande avanço a partir do fim dos anos 70 no Brasil. Assim, a evolução da Medicina Fetal, multidisciplinar, está relacionada à incorporação das técnicas de diagnósticos e terapêuticas intrauterinos e, embora existam estudos relacionados à anencefalia e seus desdobramentos para a saúde da criança, da mulher e da família, as condutas ainda são estabelecidas de forma individual e subjetivas e muitas vezes não respeitam o direito à saúde e o direito de escolha da mulher. ${ }^{(8)}$

Observa-se que a partir das Conferências de População em Desenvolvimento (Cairo, 1994), e a 4⿳亠丷厂 Conferência Mundial da Mulher (Pequim, 1995), os direitos sexuais e os direitos reprodutivos passaram a ser tratados sob a

(6) FREITAS, Teixeira de. Bioética e biodireito: a questão do aborto anencefálico. 2005. Disponível em: <http://www.biodireito-medicina.com.br/website/internas/anencefalia.asp?idAnencefalia=168> . Acesso em: 20 nov. 2006.

(7) ALMEIDA, A. M. Bioética e biodireito. Rio de Janeiro: Lumen Juris, 2000.

(8) MORON, A. F.; CHA, S. C.; ISFER, E. V. (Eds.). Abordagem multiprofissional em medicina fetal. São Paulo, 1996. 
ótica dos direitos humanos e passa ser dever do Estado garantir condições concretas para o exercício desses direitos, por intermédio de leis e políticas públicas. ${ }^{(9)}$

\section{SOBRE OS DIREITOS DA MULHER}

Para Barroso obrigar a mulher a levar uma gestação adiante nesses casos é uma espécie de tortura psicológica, pois se impõem à mãe que ela porte por mais seis meses a frustração de não ter o filho que desejava, sendo isso um castigo cruel. Para ele, a mulher deve ter o direito assegurado de escolher se leva ou não a gestação até o final. ${ }^{(10)}$

Entender que o dano psíquico padecido por mulher grávida, portadora de anencéfalo, não merece especial atenção porque o sofrimento engrandece a condição humana constitui, sem dúvida, uma postura religiosa que merece respeito, mas que não pode ser traçada como regra a ser seguida por todas as mulheres. Suportar o sofrimento como ato de purificação da alma tem incontestável conotação cristã. É evidente que não cabe ao direito a pretensão de extirpar da existência humana todas as formas de sofrimento, mas não é menos evidente que não lhe incumbe impô-las. Além disso, não há como fugir da inafastável diferença entre sofrimento voluntário e involuntário.

Mas o que, em matéria de anencefalia, seria pertinente à área jurídica, excluídos os círculos da moral e da religião? Por óbvio, é tarefa indiscutível do direito assegurar à gestante de anencéfalo o seu direito de decidir pela preservação ou não do processo de gravidez. Essa opção encontra assento em regras constitucionais bastante explícitas, tais como o direito à liberdade, em seu sentido mais amplo, o direito à autonomia da vontade, o direito à saúde e, sobretudo, o direito à dignidade da pessoa humana. Além disso, não se pode esquecer que o Estado Democrático de Direito pressupõe a realidade de uma sociedade plural. Toda vez em que se tenta romper o muro de separação entre direito e moral, ou entre direito e cultura, ou entre direito e religião, o princípio fundante do pluralismo político (art. 1ํ, V da CF) passa por sério perigo de deterioração, e, por via de consequência, o mesmo ocorre com o próprio princípio da dignidade humana.

Leis vigentes em alguns países, como Portugal, consideram lícito interromper a gravidez em função do tempo de gestação e de recomendações médicas, psicológicas, sociais ou econômicas. Trata-se de locais onde o entendimento é em favor do direito de opção da mulher, o qual se encontra descrito no corpo de suas Constituições.

(9) BARSTED, L. L. Memória do Seminário Direito ao Aborto: uma questão de justiça social. [elaborado por] Marta Rovery de Souza. Goiânia: Grupo Transas do Corpo, 2004. (Série Argumentos Feministas; 1).

(10) BARROSO, L. R. Temas de direito constitucional. 2. ed. Rio de Janeiro: Renovar, 2002. 
Em alguns países, após decisão da mãe e do médico, a gestante é submetida a um acompanhamento psicológico, sendo que a interrupção da gestação deverá ocorrer num prazo mínimo, em casos de dano à saúde da mãe, não há condicionamento a nenhum prazo. Conta-se com a gratuidade por parte do Estado desse procedimento. ${ }^{(11)}$

O Código Penal Brasileiro define aborto como sendo a interrupção ilícita da gravidez. O necessário ou terapêutico é o praticado por médico com o escopo de salvar a vida da gestante e o moral ou humanitário, oriundo de gravidez indesejada resultante de estupro (art. 128, inc. I e II, do C.P.). Já o aborto considerado criminoso está capitulado em nosso Código nos arts. 124 a 127, com ou sem o consentimento da gestante e as cominações desses casos, que podem implicar resultados lesivos à gestante, tais como lesões corporais graves e até a morte ${ }^{(12)}$. Dentre as tentativas para reformulação desse Código está o projeto de emenda de autoria do deputado Rafael Guerra, restringindo a autorização legal à hipótese de anencefalia. Nessa hipótese há evidência clínica embasada em técnica de diagnóstico complementar de que o nascituro apresenta anencefalia e o aborto é precedido de consentimento da gestante.

Os fetos anencéfalos não estão vivos, o que explica que seja considerado como "antecipação terapêutica do parto" e não de "aborto" em sentido técnico-jurídico. Por isso, não está previsto nos arts. 124 a 127 do CP e não figura como excludente no rol do art. 128 do CP que possibilita o aborto em caso de estupro ou de risco de vida para a gestante. Nesses casos, admite-se o feto vivo e, por si só, considerar um feto em qualquer estágio da gravidez como vida merecedora de proteção jurídica é bastante problemático, mas, em razão das circunstâncias, optou-se por não impedir a sua retirada. Já no caso da anencefalia, não há que se falar em "vida intra-uterina". Para que seja considerada a existência de vida, é necessária atividade cerebral, pois, sem atividade cerebral, o indivíduo é considerado morto, conforme a Lei n. 9.434/97. O feto anencéfalo não tem um cérebro, logo não chega a ter vida. ${ }^{(13)}$

É necessário esclarecer novamente que não há que se confundir a interrupção da gravidez devido a anencefalia, com o aborto eugênico, quando as mulheres são obrigadas a abortar por questões raciais, étnicas, religiosas ou discriminatórias, e que sob hipótese alguma, é defendida neste estudo. A interrupção da gravidez, aqui, tem por pressuposto ético a autonomia reprodutiva, ou seja, a decisão deve ser livre e individual, sem que haja qualquer tipo de constrangimento.

(11) MONTEIRO, W. B. Curso de direito civil: parte geral. 39. ed. São Paulo: Saraiva, 2003. v. 1, p. 362. (12) BARROSO, L. R. Artigos, pareceres, memoriais e petições. Disponível em: <http:// www.planalto.gov.br/CCIVIL_03/revista/Rev_70/Artigos/Art_Luis.htm>. Acesso em: 21 nov. 2006. (13) SIMON, H. S. Antecipação terapêutica do parto e os direitos fundamentais. Observatório Constituição \& Democracia, n. 1, jan. 2006. 


\section{ASPECTOS MÉDICOS}

A partir da incorporação da tecnologia pela medicina no decorrer do último século, tais como o diagnóstico por imagens, ampliou-se a capacidade de diagnosticar com precisão as situações de risco à saúde.

O uso e a evolução da ultrassonografia na medicina e a utilização de múltiplos parâmetros são fundamentais no caso em questão, pois oferecem menor margem de erro e possibilita a identificação precoce dos desvios do crescimento fetal, das alterações que podem distorcer o crânio, bem como estimar a idade gestacional. Com o avanço tecnológico, esses exames começam a ter imagens em três dimensões, o que aumenta ainda mais a segurança dos diagnósticos intra-úteros das má-formações fetais. Um exame de ultrassom pode dar o diagnóstico de anencefalia na12 ${ }^{2}$ semana, dado que o fechamento do tubo neural ocorre em 3 a 4 semanas após a concepção.

A anencefalia é uma má-formação congênita que se caracteriza geralmente pela ausência da abóbada craniana e massa encefálica. Sua característica principal é a má-formação do tubo neural, ou seja, no desenvolvimento embrionário não acontece o fechamento da calota craniana. Em detalhes, ocorre à ausência completa ou parcial do cérebro decorrente de falha de fechamento da porção cefálica do tubo neural, subsequente degeneração do tecido craniano, que se mantém em contato com o líquido amniótico, resultando em anencefalia. Trata-se, portanto, da mais chocante má-formação, sendo incompatível com a vida extra-uterina.

Outro dado importante é que a anencefalia é um acaso genético que pode ocorrer entre mulheres ricas e pobres; trata-se de um problema da embriogênese que ocorre muito precocemente na gestação, causado por interações complexas entre fatores genéticos e ambientais. ${ }^{(14)}$

A gestante de um feto anencéfalo é considerada portadora de uma gravidez de risco, já que pode evoluir com um ou mais dos distúrbios. Assim, sua saúde e bem-estar ficam comprometidos, não há como não cogitar que a vida da gestante esteja em risco. ${ }^{(15)}$

É inquestionável que a saúde psíquica da mulher passa por graves transtornos após o diagnóstico da anencefalia, que contagia a si própria e a seu núcleo familiar. A gravidez é uma fase de transição na vida de uma mulher, em que há grandes transformações físicas e vulnerabilidade emocional. A gestante portadora de um feto anencefalo, pode experimentar sentimentos de choque, negação, tristeza, raiva e ansiedade. Assim, uma equipe multidisciplinar evidencia a importância dos aspectos emocionais da

(14) DIAS, M. S.; PARTINGTON, M. Embryology of myelomeningocele and anencephaly. Neurosurg Focus, v. 16, p. 1-16, 2004.

(15) FEBRASGO ANENCEFALIA: POSIÇÃO DA FEBRASGO. Disponível em: <http://www. febrasgo.org.br/anencefalia1.htm>. Acesso em: 21 nov. 2006. 
família e faz com que toda a equipe seja cuidadosa em relação a esses aspectos, respeitando o difícil momento que eles enfrentam. ${ }^{(16)}$

Com o avanço tecnológico e a possibilidade de se fazer o diagnóstico nos 3 primeiros meses de gestação, cria-se o dilema: o que fazer com a condução da gravidez para a qual foi diagnosticado um feto anencéfalo, uma vez que eles "morrem" intra-útero ou durante o parto e a expectativa de vida para aqueles que sobrevivem é de apenas poucas horas ou dias? Por sua gravidade e importância, as decisões decorrentes da resposta para essa pergunta são urgentes. ${ }^{(17)} A$ interrupção da gravidez nos casos de anencefalia não deveria precisar sequer de autorização, porque se trata de um feto inviável, porque somente sobrevive às custas do corpo da mulher/mãe. Com medo de sofrer eventual penalidade, os médicos se negam a realizar, para a mulher que vai até a rede de saúde, a interrupção da gestação de uma criança anencéfala.

\section{PRINCÍPIO DA PREVENÇÃO EM SAÚDE PÚBLICA}

O princípio da prevenção tem como fundamento constitucional o disposto no art. 198, II, da CF/88, na medida em que expressamente se refere à prioridade para as atividades preventivas em prol da saúde da população. Ressalta-se que é dever do Estado tomar medidas preventivas em relação aos riscos sanitários, o que deve ser garantido mediante políticas sociais e econômicas que promovam e protejam a saúde, mas não se descarta o dever de cuidado individual.

Prevenção é o agir antecipado e, para tal, é necessário ter informação e certezas científicas dos efeitos. Em prevenção sanitária, há a obrigatoriedade legal de tomada de cuidados preventivos, pois há a certeza das consequências indesejáveis, e são antecipadas medidas para que elas não ocorram. Assim, os médicos devem observar tal princípio mesmo que os danos ainda não sejam aparentemente graves.

Cientificamente, são comprovados os danos causados à mulher por uma gravidez de um feto com anencefalia, mas as incertezas causadas pela correlação de forças da sociedade de cunhos ético, moral, religioso e outras que influenciam toda a atmosfera que envolve o caso, colocam em dúvida a inviabilidade de vida extra-uterina do feto.

(16) SETUBAL, M.S.V.; BARINI, R.; ZACCARIA, R.; SILVA, J.L. Pinto e. Relação psicológicas diante da complicada por uma malformação fetal. Soc. Brás. Méd Fetal, n. 7, 2001.

(17) BERNARDETT (DE L. DA C. R.) Espírito Santo. In: SEMINÁRIO SAÚDE REPRODUTIVA, ABORTO E DIREITOS HUMANOS, Rio de Janeiro, set. 2005. Coordenação editorial Gleyde Selma da Hora e Suelyemma Franco. Anais... Rio de Janeiro: ADVOCACI, 2005. p. 71-77. 


\section{DA DECISÃO PARADIGMÁTICA - MEDIDA CAUTELAR NA ADPF N. 54/DF(18)}

Desde meados de 2004, o tema da interrupção da gravidez de uma gestação de feto anencefálico está sendo debatido em uma ADPF, no Supremo Tribunal Federal, cujo relator é o ministro Marco Aurélio de Mello. Ele deferiu liminar na ADPF autorizando a interrupção da gravidez de feto anencefálico, mas este ato, posteriormente, foi cassado por maioria de votos em acatamento à proposta do ministro Eros Grau, devido ao instrumento utilizado para a petição. O julgamento final do mérito da ação, até os dias de hoje, ainda não foi iniciado. Em consequência, Tribunais de todo o país vêm decidindo a respeito do tema - ora permitindo, ora negando autorização à interrupção de gravidez.

Simon faz um histórico do problema e evidencia que os juízes negavam a autorização para interrupção da gravidez "sob o argumento de que não havia previsão legal para o pedido, pois as únicas excludentes de ilicitude para o crime de aborto são aquelas previstas pelo artigo 128 do CP”. Em instâncias superiores, começou-se a conceder a autorização. Entre o ingresso do pedido da autorização, audiências, recursos, apelações e mudança de instâncias jurídicas, o tempo levado era o bastante para a gestante parir um feto anencéfalo.

ADPF é a ferramenta do direito utilizada para questionar, dentre outras, a constitucionalidade de normas anteriores à promulgação de uma constituição. Sua criação teve por objetivo suprir a lacuna deixada pela ação direta de inconstitucionalidade (ADI). Tanto a legitimação ativa (art. 103, I a IX da CF) como os efeitos da decisão (art. 28 § único da Lei n. 9.868/99) são idênticos aos da $A D I$, que não pode ser proposta contra lei ou atos normativos que entraram em vigor em data anterior à promulgação da Constituição Federal de 1988. Assim, a ADPF tem por objetivo evitar ou reparar lesão a preceito fundamental, resultante de ato do poder público, bem como quando for relevante o fundamento da controvérsia constitucional sobre lei ou ato normativo federal, estadual ou municipal, incluídos os anteriores à Constituição. ${ }^{(19)}$

Na primeira hipótese cuida de ação em face de ato in genere praticado pelo Poder Público contra um ato efetivo do Poder Público. O Poder Público pratica um ato ilegítimo, violando preceito fundamental da Carta da República, cujos efeitos lesivos podem ser evitados ou reparados por meio da ADPF. Na segunda hipótese, permite-se atacar, in abstracto, lei ou ato normativo federal, estadual ou municipal, anteriores ou posteriores à Constituição, cuja

(18) ARGUIÇÃO de Descumprimento de Preceito Fundamental. Decisão monocrática. DJU, Seção I, 2 ago. 2004. Publicado também em: Informativo no 354 STF, 28 jun. a 02 jul. 2004.

(19) DINIZ, M. H. Norma constitucional e seus efeitos. 2. ed. São Paulo: Saraiva, 1992. p. 98-103. 
controvérsia tenha fundamento relevante. Anote-se que, nesse caso, não se exige, para a propositura da ADPF, a prática de um ato in genere pelo Poder Público - basta a existência de uma controvérsia constitucional sobre lei ou ato normativo federal, estadual ou municipal, incluídos os pré-constitucionais.

A ADPF é uma modalidade de arguição principal (abstrata) de constitucionalidade, instituída pelo $\S 1^{\circ}$ do art. 102 da CF, posteriormente regulamentada pela Lei $n$. 9.882/99. Não se afigura como modalidade incidental de controle, não obstante vários autores postulem em sentido inverso. Não é pré-requisito obrigatório de admissibilidade da ADPF a demonstração de controvérsia relevante sobre a lei objeto da demanda, ao contrário do que ocorre com a ação declaratória de constitucionalidade (art. 14, III da Lei n. 9.868/99), que mutilada pelos vetos, perdeu completamente a característica de arguição incidental.

No caso da ADPF n. 54/DF, colocou-se em discussão a interrupção da gestação de feto anencéfalo, com a pretensão de que o Tribunal adotasse expressamente o direito da mulher de interromper a gestação em situações de feto com anencefalia, dentre as causas de justificação para o aborto especificadas no Código Penal (20) O ministro Marco Aurélio de Mello, em 2004, conferiu a liminar sensibilizado com o fato de que "a permanência do feto mostra-se potencialmente perigosa, podendo ocasionar danos à saúde e à vida da gestante"(21). Ele também reconheceu a dor, a angústia e a frustração da mãe forçada a parir um bebê que sabe, com certeza, que não sobreviverá.

Em 2005, o Plenário do STF reuniu-se e cassou a liminar, por maioria, para julgamento do mérito, tendo o ministro Carlos Ayres Brito pedido vista dos autos para a discussão da adequação do meio escolhido ADPF para o objetivo buscado. Entendeu-se que não era o caso de manter-se a liminar com efeitos ex nunc (decisão sem efeito retroativo), mas ainda estava pendente discussão sobre legitimidade do veículo processual escolhido para a ação.

O Conselho Nacional de Saúde (CNS) aprovou a Resolução n. 348, apoiando a ADPF n. 54/DF na questão dos direitos da mulher, indicando a necessidade de implementação de políticas de saúde a serem desenvolvidas pelo Sistema Único de Saúde. Tais políticas devem atender e fazer o acompanhamento dos transtornos no decorrer da gravidez e durante o parto, além da assistência aos prováveis distúrbios psíquicos decorrentes de gravidez de feto anencefálico.

O parecer do Conselho Federal da Ordem dos Advogados do Brasil $(\mathrm{OAB})$, cujo relator foi Arx Tourinho, considerou, por maioria de votos, que a

(20) VELLOSO, C. O aborto do feto anencéfalo. Folha de S. Paulo, São Paulo, 04 nov. 2004. (21)MELLO, M. A. M. F. "A dor a mais". Folha de S. Paulo, São Paulo, 29 out. 2004. 
interrupção da gravidez de feto anencefálico não é considerada prática abortiva. A decisão da OAB acompanhou o voto do relator, que invocou o princípio da dignidade da pessoa humana em favor da gestante em interromper a gestação de um feto anencéfalo, pois o contrário é ignorar os avanços da ciência e os transtornos causados pela gestação de risco onde o "feto não possui qualquer condição de sobrevida". Nesse sentido, a gestante tem direito de interromper a gravidez, "valendo-se de seu direito à saúde e em atenção aos princípios constitucionais da liberdade e da dignidade da pessoa humana". E faz referência às mulheres pobres que usam os serviços públicos de saúde porque delas são exigidos alvarás de autorização para se fazer o procedimento de interrupção. ${ }^{(22)}$

\section{CONSIDERAÇÕES FINAIS}

Nenhum procedimento que garanta a integridade física e psicológica da mulher conflita com as normas constitucionais, principalmente com os princípios constitucionais da liberdade e preservação da autonomia da vontade, da legalidade, do direito à saúde e da dignidade da pessoa humana, pois a submissão à vontade estatal denegatória resulta em violência aos princípios comentados, de forma física, moral e psicológica. Deve-se esclarecer, explicar detalhes sobre a patologia e respeitar a decisão da mulher e da família, que pode ser baseada, também, em fatores religiosos.

À luz dos direitos humanos e reprodutivos, torna-se necessário garantir a essas mulheres condições dignas e seguras para a resolução da gestação. O sofrimento psicológico ocasionado pela ansiedade com relação ao término da gravidez, em uma situação onde não haverá as esperadas recompensas da maternidade, é enorme. É importante ressaltar que o final da gravidez representa um período de risco gestacional particular, associado a situações de risco para a vida materna.

Não existe vedação legal para antecipação terapêutica do parto no ordenamento jurídico. O que de fato ocorre é a liberdade de escolha e a autonomia da vontade da gestante em face da cláusula constitucional genérica da liberdade no direito brasileiro.

É necessária a efetivação das comissões de éticas dos serviços de saúde, a formalização de um protocolo de cuidados e a confirmação do diagnóstico por, pelo menos, três profissionais capacitados. Tais profissionais deverão prestar esclarecimento e informação a gestantes e seus familiares, contribuindo, assim, para a tomada de decisão sobre qual caminho tomar: levar a gestação até os nove meses ou interrompe-la.

(22) BRASIL. Ministério da Saúde. Conselho Nacional de Saúde. A prática do controle social: Conselhos de Saúde e financiamento do SUS. Reimpressão. Brasília: Ministério da Saúde, 2002. 
Qual seja a decisão da gestante e de seus familiares, o Estado tem que estar preparado para atender com qualidade e presteza, devendo a mulher ser cuidada como gestante de risco em uma unidade de saúde que tenha aporte técnico e tecnológico para garantir seu tratamento e a recuperação da sua saúde.

Embasados pela decisão tomada pela mãe, os procedimentos a serem realizados deverão estar ligados aos fundamentos da dignidade da pessoa humana ditados pela Constituição Federal e aos preceitos do princípio da prevenção na efetivação da proteção que antes de tudo é prevenir a integridade física e mental da mulher. Todos os procedimentos médicos e dos profissionais de saúde visam prevenir a morbidade e mortalidade materna.

A anencefalia pode ser detectada no exame de ultrasson com precisão e é de total incompatibilidade com a vida extra-uterina. Por isso, o critério da morte cerebral ou encefálica não pode ser usado, porque esse feto não dispõe de cérebro e é despojado de toda capacidade biológica para a concretização de uma vida humana viável.

Do ponto de vista bioético, pode haver um conflito de valores entre a mãe gestante e o feto anencéfalo; contudo, se este não tem nenhuma viabilidade, o conflito inexiste, a mulher gestante de feto anencéfalo tem o direito de decidir pela manutenção ou não da gravidez e não ultraja a bioética (autonomia, justiça, beneficência e não-maleficência).

Não se pode confundir assunto moral ou religioso com questionamento jurídico. Não compete ao Estado laico, dentro de uma sociedade pluralista, decidir sobre o assunto. Entretanto, a opção da mulher pela interrupção da gravidez deve atender a considerações morais ou a preceitos religiosos. Ressalta-se que não é possível caracterizar essa interrupção como aborto, uma vez que o elemento básico para o reconhecimento da existência de vida humana intra-uterina não existe e inviabiliza a própria vida após o parto.

$\mathrm{Na}$ visão médica, a gravidez de anencéfalo provoca riscos de caráter físico, social e transtornos de natureza psíquica à mulher gestante. A intervenção médica deve ser nivelada a outros procedimentos médicos como gravidez molar, gravidez ectópica, afecção uterina oncológica, e outros que não se enquadram no tipo de aborto, que são condutas tidas como atípicas. E em se tratando de um caso de atipicidade, não há sentido algum em se exigir autorização judicial para a realização, pelos médicos, dos atos interruptivos da gravidez. Trata-se formalmente de uma mera relação médico/ paciente, ou seja, de um lado diagnósticos, indicação e tratamento e, de outro, o consenso informado, consciente, livre e responsável do direito da mulher de escolher, mantendo o direito à saúde e à dignidade preservados.

Como os processos jurídicos podem levar mais tempo que o esperado, e, portanto, ocorrer a consequente utilização tardia do art. 128 do Código 
Penal, a mulher poderá sofrer toda a gravidade que envolve o caso e até mesmo evoluir para morte materna ou ainda apresentar sequelas irreparáveis, porque o aguardo foi demasiado e a intervenção na saúde da mulher já estava comprometida.

O médico deve, como profissional de saúde, lançar mão dos princípios da saúde pública para agir em benefício da mulher, que sofre com o risco de uma gravidez de um feto anencéfalo. Sua ação, apesar de ter todo um resguardo legal, não precisa estar originada em uma decisão jurídica e sim, na escolha da mulher em permanecer com a gestação até os noves meses ou interrompe-la. $\mathrm{O}$ ato médico deve estar comprometido com o bem-estar físico e mental da mulher.

\section{REFERÊNCIAS BIBLIOGRÁFICAS}

ALMEIDA, A. M. Bioética e biodireito. Rio de Janeiro: Lumen Juris, 2000.

ARGUIÇÃO de Descumprimento de Preceito Fundamental. Decisão monocrática. DJU, Seção I, 2 ago. 2004. Publicado também em: Informativo n. 354 STF, 28 jun. a 02 jul. 2004.

BARROSO, L. R. Artigos, pareceres, memoriais e petições. Disponível em: <http://www.planalto.gov.br/CCIVIL_03/revista/Rev_70/Artigos/Art_Luis.htm>. Acesso em: 21 nov. 2006.

2002.

Temas de direito constitucional. 2. ed. Rio de Janeiro: Renovar,

BARSTED, L. L. Memória do Seminário Direito ao Aborto: uma questão de justiça social. [elaborado por] Marta Rovery de Souza. Goiânia: Grupo Transas do Corpo, 2004. (Série Argumentos Feministas; 1).

BERNARDETT (DE L. DA C. R.) Espírito Santo. In: SEMINÁRIO SAÚDE REPRODUTIVA, ABORTO E DIREITOS HUMANOS, Rio de Janeiro, set. 2005. Coordenação editorial Gleyde Selma da Hora e Suelyemma Franco. Anais... Rio de Janeiro: ADVOCACI, 2005. p. 71-77.

BRASIL. Ministério da Saúde. Conselho Nacional de Saúde. A prática do controle social: Conselhos de Saúde e financiamento do SUS. Reimpressão. Brasília: Ministério da Saúde, 2002.

DIAS, M. S.; PARTINGTON, M. Embryology of myelomeningocele and anencephaly. Neurosurg Focus, v. 16, p. 1-16, 2004.

DINIZ, D.; DIAULAS, C. R. Aborto por anormalia fetal. Brasília: Letras Livres, 2004.

DINIZ, M. H. Norma constitucional e seus efeitos. 2. ed. São Paulo: Saraiva, 1992. p. 98-103. 
FEBRASGO ANENCEFALIA: POSIÇÃO DA FEBRASGO. Disponível em: <http:/ /www. febrasgo.org.br/anencefalia1.htm>. Acesso em: 21 nov. 2006.

FREITAS, Teixeira de. Bioética e biodireito: a questão do aborto anencefálico. 2005. Disponível em: <http://www.biodireito-medicina.com.br/website/ internas/anencefalia.asp?idAnencefalia=168>. Acesso em: 20 nov. 2006.

MELLO, M. A. M. F. "A dor a mais". Folha de São Paulo, São Paulo, 29 out. 2004.

MIRANDA, P. Tratado de direito privado: parte especial. 3. ed. Rio de Janeiro: Editor Borsoi, 1971. t. 7.

MONTEIRO, W. B. Curso de direito civil: parte geral. 39. ed. São Paulo: Saraiva, 2003. v. 1.

MORON, A. F.; CHA, S. C.; ISFER, E. V. (Eds.). Abordagem multiprofissional em medicina fetal. São Paulo, 1996.

PONTES, M. S. A anencefalia e o crime de aborto: atipicidade por ausência de lesividade. Disponível em: <http://jus2.uol.com.br/Doutrina/texto.asp?id=7538>. Acesso em: 24 nov. 2006.

SEBASTIANI, M. Analisis ético bajo el concepto del feto como paciente en los casos de anencefalia. Lexis NexisJurisprudência Argentina, Buenos Aires, n. 4, jul. 2003.

SETUBAL, M.S.V.; BARINI, R.; ZACCARIA, R.; SILVA, J.L. Pinto e. Relação psicológicas diante da complicada por uma malformação fetal. Soc. Brás. Méd Fetal, n. 7, 2001.

SILVA, J. A. Curso de direito constitucional positivo. 22. ed. São Paulo: Malheiros Ed., 2003.

SIMON, H. S. Antecipação terapêutica do parto e os direitos fundamentais. Observatório Constituição \& Democracia, n. 1, jan. 2006.

VELLOSO, C. O aborto do feto anencéfalo. Folha de S. Paulo, São Paulo, 04 nov. 2004. 